\title{
The ultrastructure of Ignicoccus: Evidence for a novel outer membrane and for intracellular vesicle budding in an archaeon
}

\author{
REINHARD RACHEL, ${ }^{1,2}$ IRITH WYSCHKONY, ${ }^{1}$ SABINE RIEHL ${ }^{1,3}$ and HARALD HUBER ${ }^{1}$ \\ 1 Lehrstuhl für Mikrobiologie und Archaeenzentrum, Universität Regensburg, Universitätsstr. 31, D-93053 Regensburg, Germany \\ 2 Author to whom correspondence should be addressed (Reinhard.Rachel@biologie.uni-regensburg.de) \\ 3 Present address: Aventis Behring GmbH, Emil-von-Behring-Strasse 76, D-35041 Marburg, Germany
}

Received July 9, 2001; accepted August 13, 2001; published online September 21, 2001

\begin{abstract}
Summary A novel genus of hyperthermophilic, strictly chemolithotrophic archaea, Ignicoccus, has been described recently, with (so far) three isolates in pure culture. Cells were prepared for ultrastructural investigation by cultivation in cellulose capillaries and processing by high-pressure freezing, freeze-substitution and embedding in Epon. Cells prepared in accordance with this protocol consistently showed a novel cell envelope structure previously unknown among the Archaea: a cytoplasmic membrane; a periplasmic space with a variable width of 20 to $400 \mathrm{~nm}$, containing membrane-bound vesicles; and an outer sheath, approximately $10 \mathrm{~nm}$ wide, resembling the outer membrane of gram-negative bacteria. This sheath contained three types of particles: numerous tightly, irregularly packed single particles, about $8 \mathrm{~nm}$ in diameter; pores with a diameter of $24 \mathrm{~nm}$, surrounded by tiny particles, arranged in a ring with a diameter of $130 \mathrm{~nm}$; and clusters of up to eight particles, each particle $12 \mathrm{~nm}$ in diameter. Freeze-etched cells exhibited a smooth surface, without a regular pattern, with frequent fracture planes through the outer sheath, indicating the presence of an outer membrane and the absence of an S-layer. The study illustrates the novel complex architecture of the cell envelope of Ignicoccus as well as the importance of elaborate preparation procedures for ultrastructural investigations.
\end{abstract}

Keywords: cell envelope, cellulose capillary tubes, cryo-fixation, freeze-substitution, hyperthermophilic archaea, membrane vesicles, periplasm.

\section{Introduction}

Most hyperthermophilic archaea (for a review, see Stetter 1996, 1999), in particular the Crenarchaeota, have a two-dimensional crystalline array of (glyco-)protein subunits, called the S-layer, as the main component of their cell wall (e.g., Sleytr and Messner 1988, Phipps et al. 1991, Baumeister and Lembcke 1992, Kandler and König 1993, Engelhardt and Peters 1998). In most cases, the array constitutes the outermost surface of the cells. The subunits themselves are directly anchored in the cytoplasmic membrane by stalk-like structures; the space enclosed by the cytoplasmic membrane and the $\mathrm{S}$-layer is named the quasi-periplasmic space, or simply the periplasmic space of archaea (Baumeister and Lembcke 1992, Engelhardt and Peters 1998), in analogy to the structure of many bacterial cell envelopes.

To investigate the ultrastructure by ultrathin sectioning, it is necessary to preserve the organisms in, as close as possible, their native state. In recent studies with hyperthermophilic archaea (Rieger et al. 1995, 1997), we achieved this preservation by preparing cells for electron microscopy by cultivation in cellulose capillaries, followed by high-pressure cryo-immobilization and freeze-substitution. The procedure resulted in improved structural preservation of the cells, compared with standard preparation protocols that include centrifugation, chemical fixation and dehydration at room temperature.

Here we present a detailed description of the cellular ultrastructure of Ignicoccus, a novel, recently described genus of hyperthermophilic archaea, belonging to the Desulfurococcales within the Crenarchaeota. Ignicoccus is a chemolithoautotrophic microorganism: it obtains its energy by the reduction of elemental sulfur with molecular hydrogen (Hedderich et al. 1999, Huber et al. 2000). Cells can be grown in cellulose capillary tubes to high densities and directly frozen without further processing. This approach, in combination with freeze-substitution, achieved a much improved preservation of the cell's ultrastructure and revealed a novel and rather complex type of cellular architecture not yet found in any other archaeon. In particular, we provide the first evidence for the presence of an outer membrane in an archaeal cell and for membrane-bound vesicles in its periplasm. These results are in agreement with and complementary to images of freezeetched Ignicoccus cells: the outer membrane frequently shows fracture planes, displaying a variety of intra-membranous particles, which need to be characterized in detail by biochemical and molecular methods.

\section{Materials and methods}

\section{Strains of organisms and culture conditions}

Cultures of Ignicoccus islandicus strain Kol 8 and I. pacificus strains LPC 33 and LPC 37 (Huber et al. 2000) were from the Regensburg Culture Collection. 
All strains of the genus Ignicoccus were cultivated anaerobically in modified half-strength SME medium (Huber et al. $2000)$ with the addition of $1 \%(\mathrm{w} / \mathrm{v})$ elemental sulfur. The $\mathrm{pH}$ was adjusted to $\mathrm{pH} 6.0$ with $\mathrm{H}_{2} \mathrm{SO}_{4}$. Capillary tubes were immersed in $20 \mathrm{ml}$ of culture medium in serum bottles, and the flasks pressurized with sterile gas $\left(\mathrm{H}_{2} / \mathrm{CO}_{2}(80: 20 \mathrm{v} / \mathrm{v})\right.$; $250 \mathrm{kPa}$ ). Cultures were grown at $90{ }^{\circ} \mathrm{C}$, with shaking.

The preparation and use of the cellulose tubes have been described in detail elsewhere (Rieger et al. 1997).

\section{Fixation, freeze-substitution and embedding of organisms}

Cellulose capillary tubes were cut in pieces of about $3 \mathrm{~mm}$ in length. High-pressure freezing (Müller and Moor 1984, Studer et al. 1989) of samples in the cellulose capillaries was carried out as described previously (Hohenberg et al. 1994, Rieger et al. 1997). Freeze-substitution was performed either in pure acetone, with $2 \%(\mathrm{w} / \mathrm{v}) \mathrm{OsO}_{4}$ added as a fixative, or in ethanol containing $0.5 \%(\mathrm{w} / \mathrm{v})$ uranyl acetate and $1 \%(\mathrm{w} / \mathrm{v})$ glutaraldehyde $\left(9 \mathrm{~h}\right.$ at $-90{ }^{\circ} \mathrm{C}, 6 \mathrm{~h}$ at $-60{ }^{\circ} \mathrm{C}, 3 \mathrm{~h}$ at $-30{ }^{\circ} \mathrm{C}$ and $1 \mathrm{~h}$ at $0^{\circ} \mathrm{C}$; Humbel and Müller 1986). Capillaries were washed twice in absolute acetone and infiltrated with Epon/Araldite (Luft 1961), which was then polymerized at $60^{\circ} \mathrm{C}$ for $24 \mathrm{~h}$.

In preliminary experiments, the high-pressure freezer was not used for initial immobilization of samples. Instead, cells were chemically fixed for 60 min by adding glutaraldehyde $(1.5 \%, \mathrm{v} / \mathrm{v})$ to the culture medium. Cells were collected by centrifugation, taken up in capillaries (about $25 \mathrm{~mm}$ in length), and freeze-substituted in acetone containing $\mathrm{OsO}_{4}(2 \% \mathrm{w} / \mathrm{v})$ for $24 \mathrm{~h}$ at $-80{ }^{\circ} \mathrm{C}$. The samples were kept on sublimating dry ice for $16 \mathrm{~h}$, resulting in a slow rise of the temperature from -80 to $+25^{\circ} \mathrm{C}$. Capillaries were then embedded in Epon (polymerization at $60{ }^{\circ} \mathrm{C}$ ).

For comparison of the volumes of archaeal cells (total volume, cytoplasm and periplasm), model calculations were performed with Ignicoccus cells used in this study and with cells of three species that structurally represent the three orders of the Crenarchaeota known today: Metallosphaera prunae of the Sulfolobales; Pyrolobus fumarii of the Desulfurococcales; and Pyrobaculum aerophilum of the Thermoproteales. To simplify the calculations, the cell shapes of Metallosphaera and Pyrolobus, Pyrobaculum, and Ignococcus were assumed to approximate a homogeneous sphere, a homogeneous cylinder and an ellipsoid, respectively. The periplasm of Metallosphaera and Pyrobaculum was assumed to have a constant width of $25 \mathrm{~nm}$, and that of Pyrolobus a constant width of 45 nm (Völkl et al. 1993, Fuchs et al. 1995, Blöchl et al. 1997, Rachel 1999). Because the apparent cell diameters varied considerably, depending on growth phase and section plane, we decided to perform calculations with the minimum and maximum measured values (Table 1). For Metallosphaera, Pyrobaculum and Pyrolobus, cell diameters were measured on sections from previous studies (Völkl et al. 1993, Fuchs et al. 1995, Blöchl et al. 1997). The cell length of Pyrobaculum was assumed to be constant, although it varied considerably; however, this did not influence the periplasm/cell volume ratio. For Ignicoccus, the diameters of the cells from Figure $1 \mathrm{~b}$ in Huber et al. (2000) and from Figures 3a and 3b in this paper were determined.

\section{Freeze-etching}

Cells were harvested by centrifugation (15 min at 15,000 $\mathrm{g}$; Eppendorf 5415 centrifuge). A $1.5-\mu l$ aliquot of the concentrated cell suspension was loaded into a gold-carrier and plunged into liquid nitrogen. The sample was cut with a cold knife $\left(T \leq-185^{\circ} \mathrm{C}\right)$ and etched for $4 \min \left(T=-97^{\circ} \mathrm{C} ; p \leq 1.3 \times\right.$ $10^{-5} \mathrm{~Pa}$ ) in a CFE-50 freeze-etch unit (Cressington, Watford,

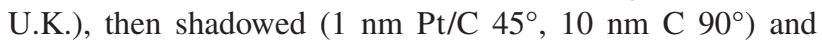
cleaned on $\mathrm{H}_{2} \mathrm{SO}_{4}(70 \%)$.

\section{Microscopy}

The transparent capillary tubes were inspected using a Zeiss Axioplan phase contrast microscope, equipped with a dry objective $(40 \times$, numerical aperture 0.75$)$ or an oil-immersion objective $(100 \times$, numerical aperture 1.3).

Transmission electron micrographs were taken on a Philips CM 12 operated at $120 \mathrm{kV}$, equipped with a Gatan TV 673 wide-angle camera (Gatan, München) in order to facilitate searching and focusing of suitable specimen areas, and with a slow-scan CCD camera linked to a computer (TVIPS, Tietz, Gauting/München) for recording images and for correction of focus and astigmatism.

\section{Enrichment and preparation of the outer sheath}

Frozen cells were thawed in MES buffer containing $10 \mathrm{mM}$ 2-( $N$-morpholino)ethanesulfonic acid/KOH, $\mathrm{pH} 6.0,1 \mathrm{mM}$ $\mathrm{MgSO}_{4}$ and $1 \mathrm{mM}$ dithiothreitol. The cells were broken by resuspending the cell pellet in deionized water. The cell envelope fragments were concentrated by centrifugation for $30 \mathrm{~min}$ at 48,000 $g$ (SS 34 rotor, Sorvall RC5-C centrifuge) and the resulting pellet layered on top of a preformed Percoll density gradient (total Percoll content: $30 \%$ ). Gradient centrifugation was performed for $90 \mathrm{~min}$ at $20,000 \mathrm{~g}$ at $4{ }^{\circ} \mathrm{C}$. The resulting bands were further purified on a $60 \%$ sucrose cushion $(23,000 \mathrm{~g}, 45 \mathrm{~min})$ and washed 5 times in MES buffer. Samples were applied to a carbon-coated copper grid and negatively stained with uranyl acetate $(3 \% \mathrm{w} / \mathrm{v})$.

\section{Results}

\section{Cultivation of Ignicoccus cells in capillaries}

As in a previous study of Pyrodictium using the same methods (Rieger et al. 1997), growth of the microorganisms inside the cellulose capillaries was monitored by incubating several flasks in parallel and examining the capillaries at defined intervals to check the cell density. Ignicoccus cells could be cultivated successfully in the capillary tubes, reaching substantially higher cell densities than when grown freely suspended in the liquid culture medium (Figure 1). Cell densities could only be estimated, because a Thoma chamber could not be used to count cells in capillaries. Based on the number of cells visible in the viewing field of a light microscope, cell densities of $10^{9}-10^{10}$ cells $\mathrm{ml}^{-1}$ were obtained, $10-100$ times higher than cell densities in liquid cultures. 
Table 1. Volume of cell, cytoplasm and periplasm in Crenarchaeota.

\begin{tabular}{|c|c|c|c|c|c|c|}
\hline Genus & $\begin{array}{l}\text { Cell dimensions } \\
(\mu \mathrm{m} \times \mu \mathrm{m})\end{array}$ & $\begin{array}{l}\text { Total cell } \\
\text { volume }\left(\mu \mathrm{m}^{3}\right)\end{array}$ & $\begin{array}{l}\text { Cytoplasmic } \\
\text { volume }\left(\mu \mathrm{m}^{3}\right)\end{array}$ & $\begin{array}{l}\text { Periplasmic } \\
\text { volume }\left(\mu \mathrm{m}^{3}\right)\end{array}$ & $\begin{array}{l}\text { Periplasm/cytoplasm } \\
\text { volume ratio }(\%)\end{array}$ & $\begin{array}{l}\text { Periplasm/cell } \\
\text { volume ratio (\%) }\end{array}$ \\
\hline \multicolumn{7}{|c|}{ Metallosphaera } \\
\hline Cell 1 & 0.48 & 0.058 & 0.042 & 0.016 & 38.8 & 28.1 \\
\hline Cell 2 & 0.91 & 0.395 & 0.333 & 0.062 & 18.5 & 15.6 \\
\hline \multicolumn{7}{|c|}{ Pyrolobus } \\
\hline Cell 1 & 0.91 & 0.395 & 0.289 & 0.106 & 36.7 & 26.8 \\
\hline Cell 2 & 1.28 & 1.098 & 0.905 & 0.193 & 21.4 & 17.6 \\
\hline \multicolumn{7}{|c|}{ Pyrobaculum } \\
\hline Cell 1 & $0.35 \times 3.05$ & 0.293 & 0.212 & 0.081 & 38.4 & 27.6 \\
\hline Cell 2 & $0.52 \times 3.05$ & 0.648 & 0.520 & 0.127 & 24.5 & 19.6 \\
\hline \multicolumn{7}{|c|}{ Ignicoccus } \\
\hline Cell 1 & $1.35 \times 1.23$ & 1.069 & 0.250 & 0.820 & 328.0 & 76.6 \\
\hline Cell 2 & $1.69 \times 1.39$ & 1.710 & 0.490 & 1.220 & 249.0 & 71.4 \\
\hline Cell 3 & $2.2 \times 1.95$ & 4.380 & 1.560 & 2.820 & 181.0 & 64.4 \\
\hline
\end{tabular}

\section{Ultrastructure of Ignicoccus cells in ultrathin sections}

In all experiments, essentially similar results were obtained with cells of the three strains of Ignicoccus (I. islandicus strain Kol8 and I. pacificus strains LPC33 and LPC37). Therefore, the results presented here can be regarded as characteristic of the ultrastructure of all members of this genus.

In preliminary experiments, cells of Ignicoccus were chemically fixed by adding glutaraldehyde to the culture medium, followed by dehydration in acetone/ $/ \mathrm{SO}_{4}$, and finally embedding in Epon (Figure 2). Ultrathin sections showed that most cells had a homogeneously, although not tightly, packed cytoplasm that was surrounded by two double-track membranes enclosing a periplasmic space of variable width, approximately 30 to $200 \mathrm{~nm}$. Defects were often observed in both membranes, i.e., the membranes were not continuous. Periplasmic vesicles were observed in one of every 10 cells. The results obtained with this preparation protocol varied from one preparation to the next: some cells had a more tightly packed cytoplasm, and the membranes were not smooth, but irregular or undulating (cf. also Figure 6b).
A different view of the ultrastructure of Ignicoccus was obtained when cryo-immobilization in a high-pressure freezer, rather than glutaraldehyde fixation, was performed before freeze-substitution. Figures $3 \mathrm{a}$ and $3 \mathrm{~b}$ show representative views of thin sections of two Ignicoccus cells grown inside the capillaries after high-pressure freezing, freeze-substitution and embedding in Epon/Araldite. Most cells were similarly well preserved and displayed the following typical features: a tightly packed cytoplasm surrounded by a smooth, rarely undulating membrane; a periplasm with a highly variable width of 25 to $400 \mathrm{~nm}$, filled with numerous membrane-bound vesicles; and an "outer sheath," most probably an outer membrane (see also Figure 1b in Huber et al. 2000). Closer inspection showed spots where the cytoplasmic membrane bulged out: here, either new periplasmic vesicles were formed, or existing vesicles fused with the cytoplasmic membrane (Figure 3c). The periplasmic vesicles appeared as round bodies (diameter $30-90 \mathrm{~nm}$ ) or were elongated, with a maximum length of $300 \mathrm{~nm}$ (Figure 3d). The cytoplasmic membrane and the membranes surrounding the vesicles consistently had a clear dou-
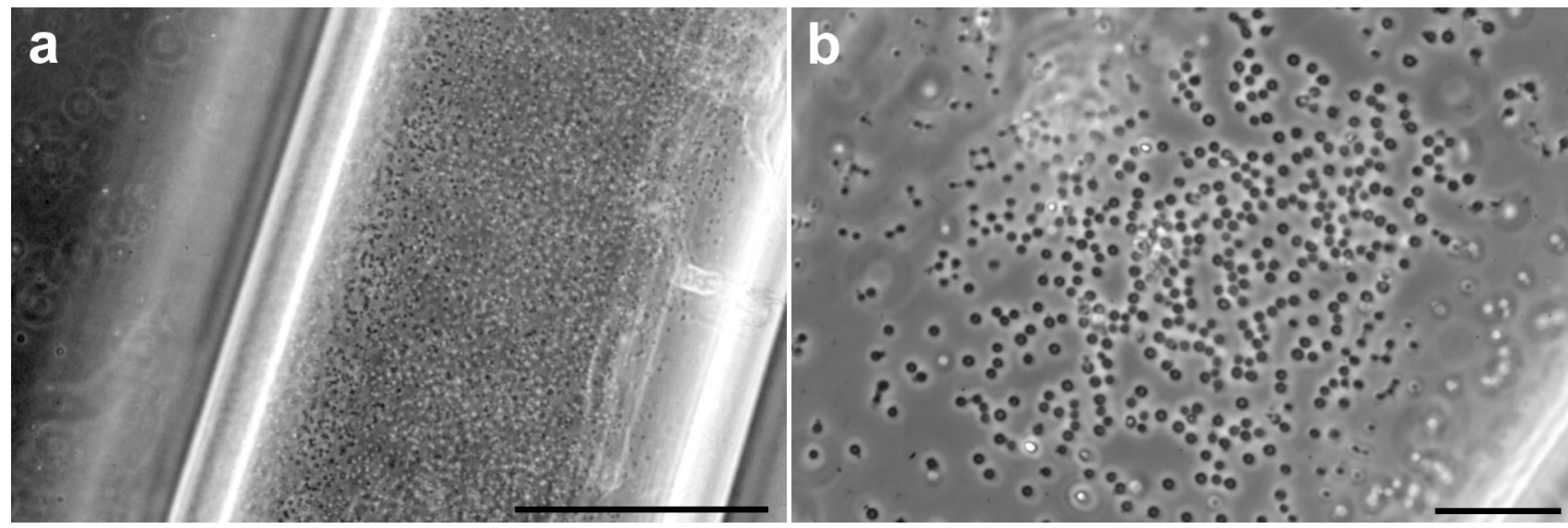

Figure 1. Light micrographs of cellulose capillary tubes, inoculated with Ignicoccus, (a) after incubation for $36 \mathrm{~h}$, bar $=100 \mu \mathrm{m}$; and (b) after incubation for $28 \mathrm{~h}$, bar $=20 \mu \mathrm{m}$. 


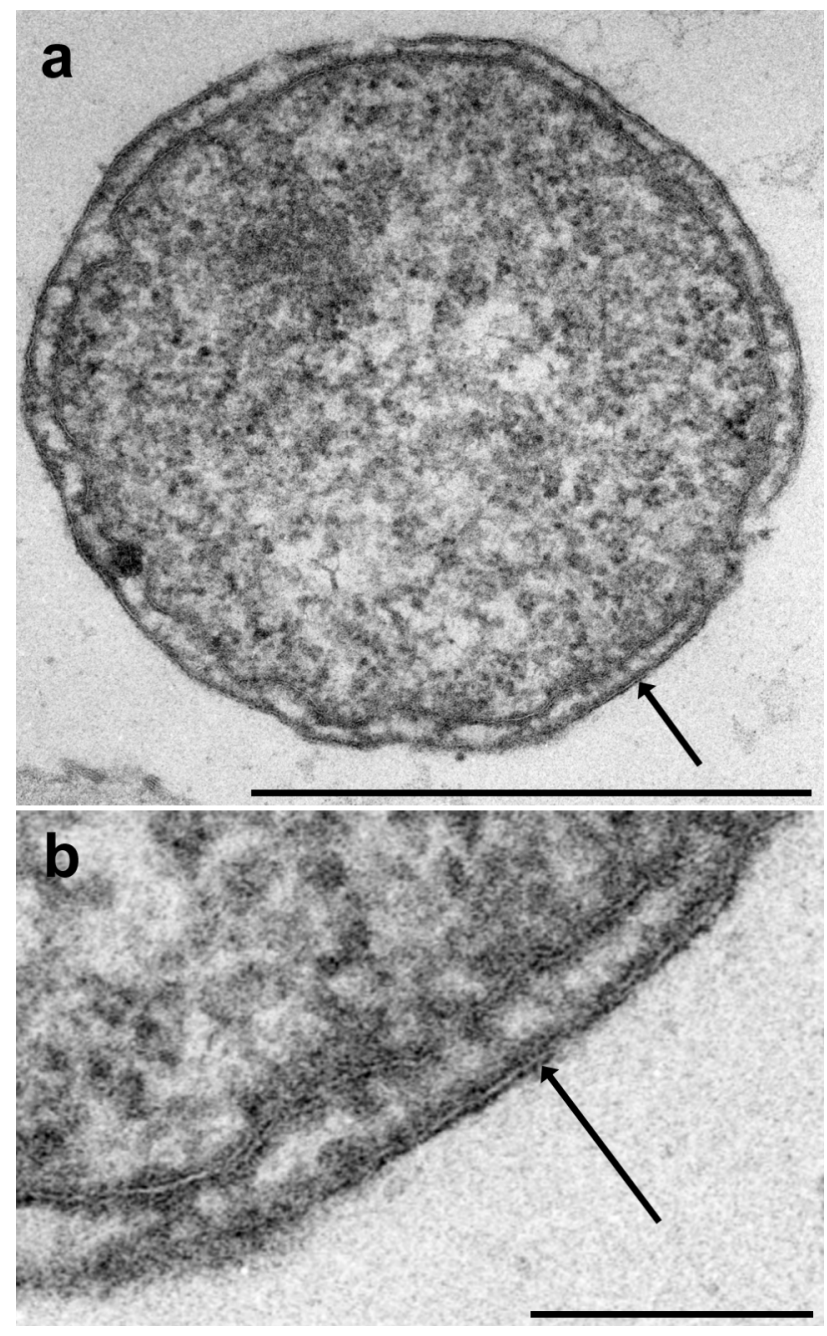

Figure 2. Electron micrographs of an ultrathin section of Ignicoccus, prepared by initial glutaraldehyde fixation, freeze-substitution, and embedding in Epon; arrows point to the outer membrane; (a) bar = $1 \mu \mathrm{m}$; and (b) detail at higher magnification, $\mathrm{bar}=0.2 \mu \mathrm{m}$.

ble-track appearance, whereas the outer membrane was usually a 9- to 10-nm-thick line; only occasionally, at higher magnification, was a weak double-track appearance discernible. Most cells were in good condition, as evidenced by a tightly packed cytoplasm and intact membranes. When cells showed signs of autolysis, the outer membrane was usually still intact, but the cytoplasmic membrane was discontinuous in some spots, i.e., damaged: the cytoplasm was stained homogeneously, although less densely, whereas the periplasm was stained darker, still containing intact vesicles.

Model calculations, as outlined in Materials and methods, indicated that the total volume of Ignicoccus cells (see Table 1) was about $1.0-4.4 \mu^{3}$. The cytoplasm occupied about $23-36 \%$ and the periplasm about $64-77 \%$ of this volume, i.e., the volume of the periplasm was 1.8-3.3-fold greater than that of the cytoplasm. Results of similar calculations of coccoid and rod-shaped cells of the Crenarchaeota are listed in detail in Table 1; in these cells the volume of the periplasm was 16-
$28 \%$ of the total cell volume, or $0.18-0.39$ times as large as the volume of the cytoplasm.

\section{Ultrastructure of Ignicoccus cells by freeze-etching}

In micrographs of freeze-etched samples (Figure 4), a variety of different structural aspects of Ignicoccus cells were visible. Cross-fractured cells displayed a similar representation of the ultrastructure as seen in ultrathin sections shown in Figure 3. Fracture faces of the cytoplasmic membrane were not observed. Frequently, views of the cell surface were visible. The outer surface appeared smooth, with no indication of a regular pattern. The only corrugations were rare, irregularly spaced protrusions, about $16 \mathrm{~nm}$ in diameter (Figure 4a). The outer sheath was frequently fractured, as seen in Figures $4 \mathrm{a}-\mathrm{c}$ (and in Figure 1c in Huber et al. 2000), revealing its inner fracture face, and is, therefore, referred to as the "outer membrane" of Ignicoccus. This fracture face, seen from the outside, revealed a tight, but not crystalline, packing of particles of approximately $8 \mathrm{~nm}$ in diameter (Figures $4 \mathrm{a}$ and $4 \mathrm{~d}$ ). In addition, on almost all of these fracture faces, there were prominent round pores or cavities, about $16 \mathrm{~nm}$ in diameter, surrounded by a protruding round torus, about $4 \mathrm{~nm}$ thick, yielding a total particle diameter of about $24 \mathrm{~nm}$ (Figures 4a, 4b, 4d and 4f). Each of these particles was surrounded by another ring consisting of about 20 to 25 tiny particles that were faintly, but distinctly visible; the diameter of this ring was about $130 \mathrm{~nm}$ (Figures 4a and $4 d)$.

Occasionally, we found a cluster of five to eight protruding particles, arranged in an area of about $60 \times 60 \mathrm{~nm}$ (Figures $4 \mathrm{~b}$ and 4f); each particle had a diameter of $12 \mathrm{~nm}$, like the flagella of this archaeon (Huber et al. 2000).

On the complementary fracture face of the outer membrane (Figures $4 \mathrm{c}$ and $4 \mathrm{e}$ ), viewed from "inside the cell," the numerous, tightly packed 8-nm particles were more distinct. The 24-nm ring-shaped particles now appeared not as depressions, but as projections, whereas the large 130-nm ring surrounding these particles could not be discerned.

\section{Electron microscopy of outer membrane preparations}

When cell envelopes were fractionated by density gradient centrifugation, two bands, close to one another, were obtained. The lower band was enriched in the outer membrane and contained mainly membrane vesicles, which collapsed on the carbon film after negative staining and air-drying; only a few small patches of single-layered membranes were observed (Figures 5a and 5b). A prominent feature of these membranes was the presence of numerous "black dots," accumulations of negative stain in pores or cavities, approximately $2 \mathrm{~nm}$ in diameter, which appeared to be irregularly arranged in a white matrix. Boundaries of individual subunits could not be delineated. To enhance structural details, image analysis by correlation averaging (Saxton and Baumeister 1982) was applied to small single-layered patches, about $100 \mathrm{~nm}$ in diameter (Figure $5 b$, top). The resulting correlation average (Figure 5c) can be interpreted to suggest that the outer membrane contains round particles, about $8 \mathrm{~nm}$ in diameter, with a central stainfilled pore; rarely, these particles were closely packed in a hex- 

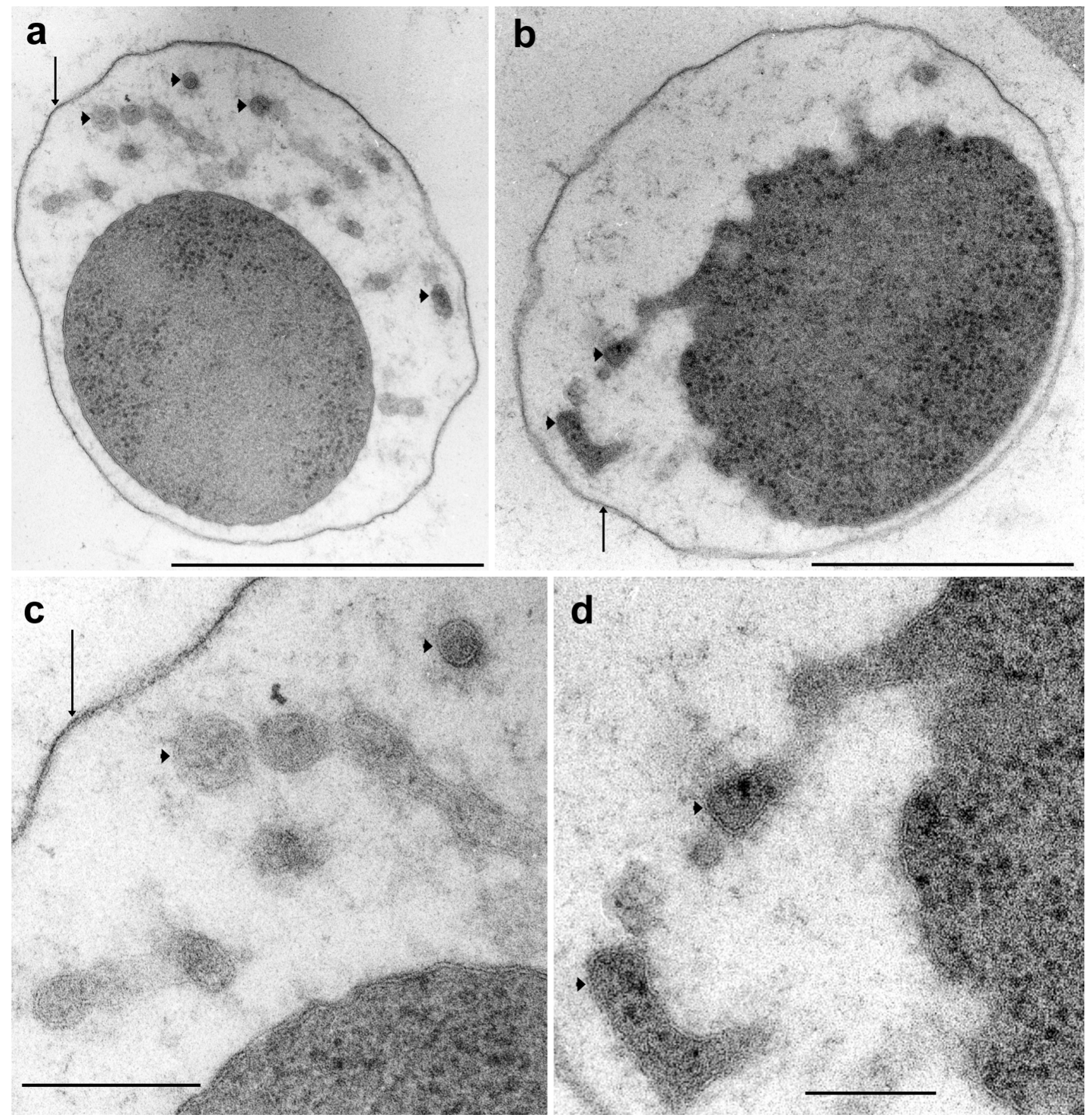

Figure 3. Electron micrographs of ultrathin sections of Ignicoccus, grown inside a capillary, high-pressure frozen and freeze-substituted. Arrowheads point to periplasmic vesicles and arrows point to the outer membrane. (a, b) Low magnification micrographs, bar $=1 \mu \mathrm{m}$; and (c, d) detail at higher magnification, bar $=0.2 \mu \mathrm{m}$.

agonal array, with a low degree of crystalline order. This arrangement resembles to some extent that of porins in outer membrane sheets of gram-negative bacteria. In addition, larger particles, about $24 \mathrm{~nm}$ in diameter, were occasionally found in the membrane sheets (Figure 5a).

\section{Observations of dividing cells}

Occasionally, dividing cells were found. The micrographs show that Ignicoccus cells start to divide by constricting the cytoplasm (Figure 6a). Later, the two cytoplasms become completely separated, but still remain enclosed in the outer membrane. At this stage, a new layer of an outer membrane is synthesized in the periplasmic space, between the two cytoplasms, as shown in Figure 6b (arrows).

\section{Discussion}

The growth behavior of Ignicoccus inside the cellulose capil- 


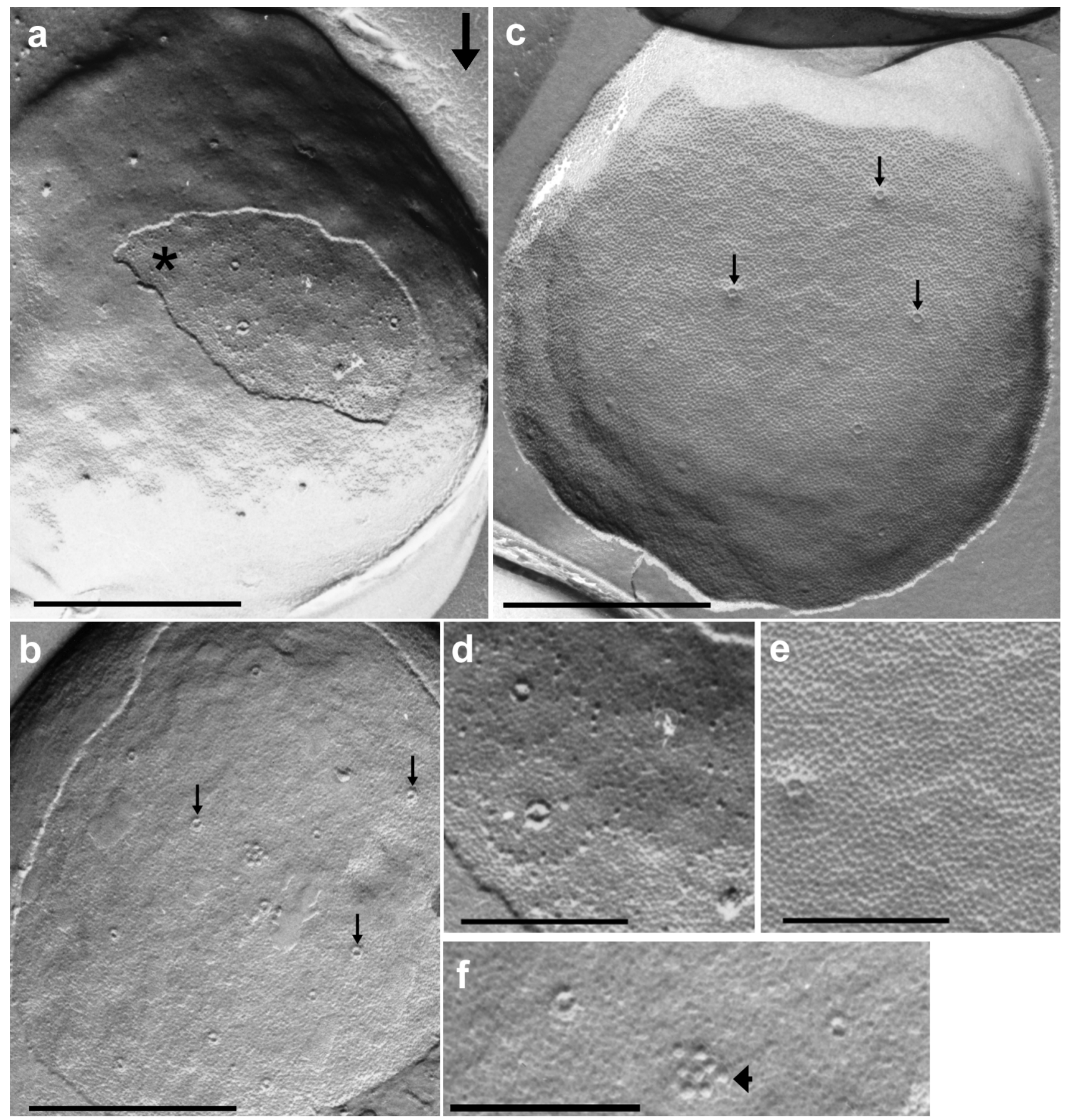

Figure 4. Electron micrographs of freeze-etched Ignicoccus. The arrow in (a) indicates the direction of the platinum shadowing. (a) View of the smooth cell surface; the star marks the area of the fractured outer membrane; bar $=0.5 \mu \mathrm{m}$. (b) View of the fractured area of the outer membrane, with 12 particles (24-nm pores), three of which are marked by arrows; bar $=0.5 \mu \mathrm{m}$. (c) View of the inner fracture face of the outer membrane, with densely packed 8-nm particles, and with at least six 24-nm pores, three of which are marked by arrows; bar $=0.5 \mu \mathrm{m}$. (d) Detail of (a) at higher magnification, with two 24-nm pores. (e) Detail of (c) at higher magnification, with one 24-nm pore. (f) Detail of (b) at higher magnification, with two 24-nm pores, and a "group-of- 8 " particle (flagella), marked by arrowheads; bar in $\mathrm{d}-\mathrm{f}=0.2 \mu \mathrm{m}$.

laries is comparable to that of other (not only hyperthermophilic) archaea. With the same technique, we have cultivated cells of many other microorganisms, including archaea (e.g., Pyrodictium, Pyrobaculum, Thermoproteus, Aeropyrum, Pyrococcus, Methanopyrus, Archaeoglobus and Halobacterium) and some bacteria (Aquifex and Thermocrinis), to high densities under anaerobic or aerobic conditions. Therefore, this method appears to be generally applicable and is not restricted to a specific type or genus of microorganism nor to a specific kind of metabolism, because heterotrophic and autotrophic, 

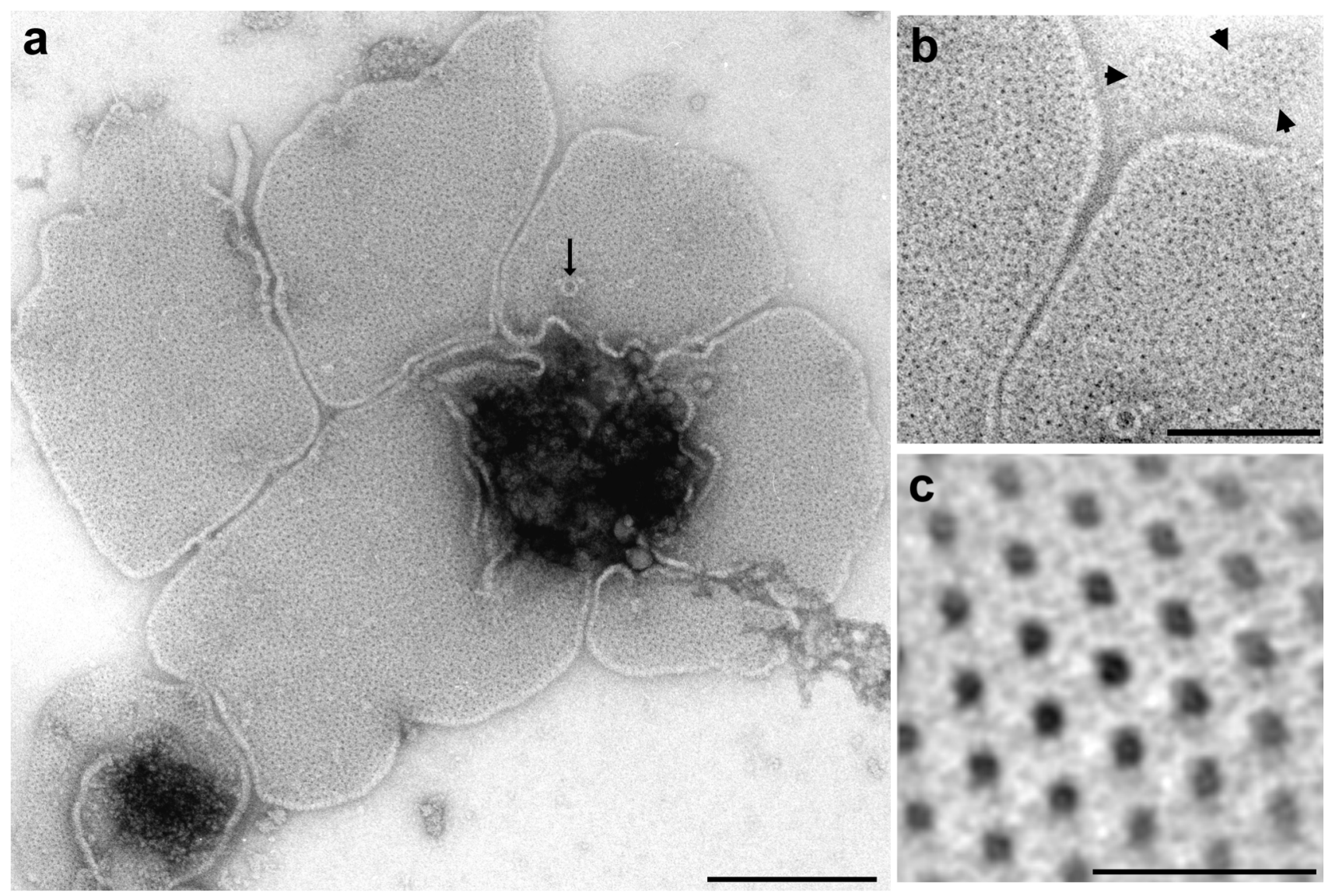

Figure 5. Electron micrograph showing a preparation enriched in outer membranes of Ignicoccus after density gradient centrifugation and negative staining with uranyl acetate. (a) Five mostly double-layered membrane patches; arrow: $24-\mathrm{nm}$ pore; bar $=200 \mathrm{~nm}$. (b) Detail of (a), contrast enhanced, at higher magnification; three arrowheads in the top right corner outline a small single-layered patch; bar $=100 \mathrm{~nm}$. (c) Correlation average of the small single-layered patch marked in (b); dark: negative stain; bar $=20 \mathrm{~nm}$.

respiring and fermenting cells can be cultivated. Even eukaryotic cells can be grown successfully in this way (Tiedemann et al. 1997).

Ultrathin sections provided insight into the ultrastructure of Ignicoccus, which turned out to be unusually complex. When cells were chemically fixed during the initial preparation step (we performed these experiments several times, with diverse modifications), we observed coccoid cells whose cell wall ultrastructure was not well preserved and was difficult to interpret without additional information. It is important to note that the results shown in Figures 2 and $6 \mathrm{~b}$ are only two examples of cells treated with glutaraldehyde. In other cells, the clear double-track feature of both membranes was not evident, and the cell envelope, consisting of the two membranes and the periplasm, was undulating, occasionally displaying periplasmic vesicles. The packing and staining of the cytoplasm and periplasm differed from cell to cell and from one preparation to another. In light of the results obtained after high-pressure freezing, at least some of these "structural features" must be regarded as artifacts caused by the slow initial chemical fixation step. At that time, we concluded that Ignicoccus cells were structurally different from other organisms in the order Desulfurococcales, such as Pyrodictium, Pyrolobus, Desul- furococcus, Aeropyrum and Stetteria; all of these organisms have a simple cell wall, consisting of an S-layer anchored in the cytoplasmic membrane.

The inconsistency of our results with chemically fixed cells prompted us to use cryo-immobilization by high-pressure freezing as the first step in the preparation of these cells, because we had successfully used this method to reliably embed Pyrodictium cells (Rieger et al. 1995, 1997). Cryo-immobilization enabled us to obtain results that were both readily interpretable and consistent from one experiment to the next. The results were also in accordance with those obtained by freezeetching: the various views of Ignicoccus cells, as seen in freeze-etched samples, complemented each other and contributed to an understanding of the cell structure observed in ultrathin sections.

The smooth outer surface of freeze-etched Ignicoccus cells, and the appearance of the isolated outer membrane sheets, did not provide any evidence for a regular pattern of a two-dimensional protein crystal (S-layer) as is found on almost all cells in the kingdom Crenarchaeota (previously, the only exception was Thermosphaera; Huber et al. 1998).

One of the most unusual features of Ignicoccus cells is the huge periplasm. Model calculations show that the volume of 

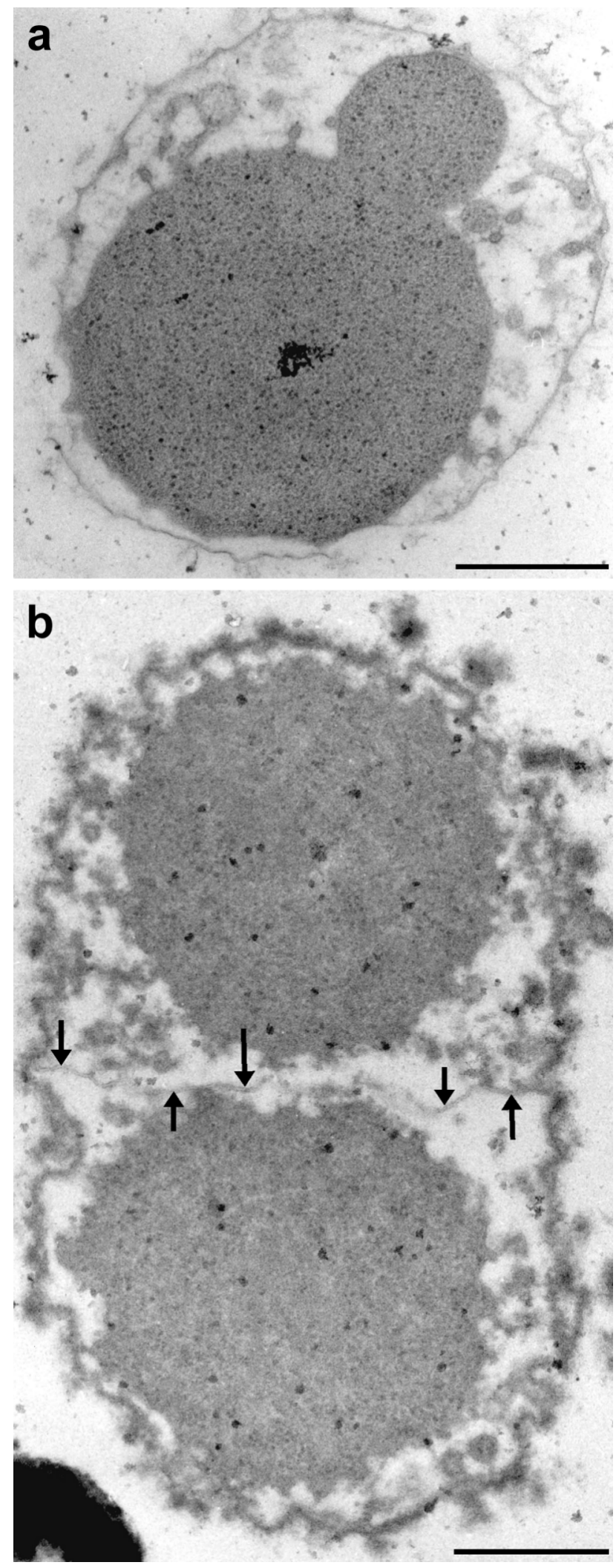

Figure 6. Electron micrographs of ultrathin sections of Ignicoccus in division, prepared by (a) high-pressure freezing and freeze-substitution, and (b) initial glutaraldehyde fixation and freeze-substitution, and embedding in Epon. Arrows point to the newly synthesized outer membrane between the daughter cells; bar $=0.5 \mu \mathrm{m}$. the periplasm in Ignicoccus cells is generally greater (1.8 to 3.3 times) than that of the cytoplasm. This contrasts sharply with the situation in all other cells of the Crenarchaeota: the volume of periplasm in cells of Metallosphaera, Pyrolobus and Pyrobaculum is approximately 0.18 to 0.39 times as great as that of the cytoplasm. Although cells investigated in these earlier studies had not been embedded by cryo-techniques, complementary experiments performed recently (G. Rieger and R. Rachel, Universität Regensberg, unpublished data) show that the width of the periplasm in these cells is not influenced by the method used for fixation and dehydration, probably as a result of the rigidity of the S-layer.

Another conclusion derived from the ultrathin sections is that Ignicoccus cells have two distinct compartments delimited by a membrane: the cytoplasm and the periplasm. The reason for the compartmentalization in this prokaryotic cell is unclear, as the cellular functions associated with the archaeal periplasm have not yet been sufficiently investigated.

It is important to recall that the huge periplasm has a highly variable width and is asymmetrically organized in Ignicoccus cells, for the evident reason that the cells are flagellated (up to nine flagella; Huber et al. 2000). The flagella need to be anchored in the cytoplasm or cytoplasmic membrane, which can be achieved only in an area where the periplasm is fairly thin. In the outer membrane fracture face, we occasionally observed a cluster of up to eight protrusions; each had the diameter of a single flagellum and can be interpreted as a "remnant" of a fractured flagellum in these areas of the cell wall. In ultrathin sections, we have not yet observed the insertion point of the flagellar bundle or a polar cap structure, which is known to exist at least in Halobacterium (Kupper et al. 1994). This would require a more detailed study using serial sectioning.

The functional significance of the periplasm and periplasmic vesicles in the context of the mode of energy metabolism of Ignicoccus is unknown. All solutes in the growth medium, i.e., ions, $\mathrm{CO}_{2}$ and $\mathrm{H}_{2}$, can be assumed to be freely accessible to the cells in the culture medium without being taken up or transported into the cytoplasm by means of membraneenclosed vesicles.

One possibility is that the vesicles function not only in import, but also in export. For example, genomic or plasmid DNA might be exported via this route for exchange of genetic material with other cells. Other molecules that must be exported out of the cytoplasm are those destined for insertion into the outer membrane, including at least the three complexes observed in micrographs of freeze-etched Ignicoccus: the numerous 8-nm particles; the 24-nm pores with the 130-nm ring; and the "group-of-8" particles. Functions associated with these molecules are as yet unknown; however, the 24-nm pores may have a function similar to that of the secretins (e.g., the XcpQ- or PilQ-complexes in Pseudomonas aeruginosa (Bitter et al. 1998, Nunn 1999)), which form large ring-like pores mediating protein transport across the outer membrane.

The three types of membranes in Ignicoccus cells can easily be differentiated in our electron micrographs. The cytoplasmic membrane does not fracture and is a clear double line in sec- 
tions. The membranes of the periplasmic vesicles also appear as a double layer, supporting the view that these vesicles are formed by bulging from the cytoplasmic membrane. In contrast, the outer membrane fractures and is a single line or a weak double line in sections. The fact that it is only seen as a clear double-track in conventional preparations cannot easily be explained; however, it may be attributable to the initial chemical fixation step and, to a greater degree, to the rigorous and deleterious removal of water, proteins and lipids during dehydration at room temperature compared with the more gentle treatment when cells are freeze-substituted (Weibull and Christiansson 1986, Graham and Beveridge 1990).

From the results obtained, it is evident that the cytoplasmic membrane and the outer membrane have some fundamental differences in their lipid and protein constituents. Initial analysis of the total lipids of Ignicoccus cells showed that they have both diether lipids and tetraether lipids (Huber et al. 2000). From their fracture behavior, we conclude that the outer membrane is composed of diether lipids, whereas the cytoplasmic membrane contains tetraether lipids (Beveridge et al. 1993), indicating some kind of lipid partitioning, as is the case in gram-negative bacteria. To prove this, it will be necessary to chemically analyze the lipid content of the two membranes separately. From the micrographs showing a late phase of a dividing cell, it appears that the building up of the outer membrane is a distinctive process, controlled in space and time.

We are aware that, at present, we have not proven that the "outer sheath" of Ignicoccus is an outer membrane, in analogy to the outer membrane of gram-negative bacteria; this can be accomplished only by thorough analysis of its lipid and protein content. Nevertheless, there is strong evidence favoring this interpretation. The fracture behavior of the "outer sheath" in freeze-etch experiments is comparable with that of membranes of many eukaryotes and prokaryotes. This fracture behavior is also a feature that differentiates the "outer sheath" from both the cytoplasmic membrane of Ignicoccus and the outer membrane of gram-negative bacteria, which are not prone to fracture in this type of experiment. The "outer sheath" is not an S-layer (no crystalline pattern and no membrane anchor). Finally, it contains a variety of "particles," most likely proteins, as visualized in freeze-etched samples and in negatively stained outer membrane preparations. In this respect, the "outer sheath" resembles the outer membrane of many gramnegative bacteria, which have been shown to be tightly packed with a variety of porin-like molecules that function as transporter molecules for all kinds of small solutes, charged and uncharged (Schirmer 1998).

We observed cells in which the periplasmic vesicles either bulge out of, or fuse with, the cytoplasmic membrane. In eukaryotic cells, these types of events are known to be controlled by rather complex machinery involving protein molecules like SNAP, NSF and SNAREs, which are necessary for mediating membrane fusion events (Söllner et al. 1993, Rothman 1996). To our knowledge, Ignicoccus is the first hyperthermophile in which intracellular vesicle formation or fusion events, or both, have been observed. The study of Ignicoccus therefore provides an opportunity to compare the pro- teins involved in these processes, at high temperatures and in the presence of archaeal lipids, with similar proteins in nonhyperthermophilic microorganisms.

\section{Acknowledgments}

The authors thank Prof. Dr. K.O. Stetter for continuous support and critical discussions, P. Hummel for excellent technical assistance, Dr. M. Müller and Dr. R. Hermann (ETH Zürich) for the opportunity to work with their high-pressure freezer, and Dr. B. Hedlund for carefully reading the manuscript. This work was supported by grants of the DFG (Ra751/1-2 to R. Rachel) and Fonds der Chemischen Industrie (to K.O. Stetter).

\section{References}

Baumeister, W. and G. Lembcke. 1992. Structural features of archaebacterial cell envelopes. J. Bioenerg. Biomembr. 24:567-575.

Beveridge, T.J., C.G. Choquet, G.B. Patel and G.D. Sprott. 1993. Freeze-fracture planes of methanogen membranes correlate with the content of tetraether lipids. J. Bacteriol. 175:1191-1197.

Bitter, W., M. Koster, M. Latijnhouwers, H. de Cock and J. Tommassen. 1998. Formation of oligomeric rings by XcpQ and PilQ, which are involved in protein transport across the outer membrane of Pseudomonas aeruginosa. Mol. Microbiol. 27:209-219.

Blöchl, E., R. Rachel, S. Burggraf, D. Hafenbradl, H.W. Jannasch and K.O. Stetter. 1997. Pyrolobus fumarii, gen. and sp. nov., represents a novel group of archaea, extending the upper temperature limit for life to $113^{\circ} \mathrm{C}$. Extremophiles 1:14-21.

Engelhardt, H. and J. Peters. 1998. Structural research on surface layers: a focus on stability, surface layer homology domains, and surface layer-cell wall interactions. J. Struct. Biol. 124:276-302.

Fuchs, T., H. Huber, K. Teiner, S. Burggraf and K.O. Stetter. 1995. Metallosphaera prunae, sp. nov., a novel metal-mobilizing, thermoacidophilic archaeum, isolated from a uranium mine in Germany. Syst. Appl. Microbiol. 18:560-566.

Graham, L.L. and T.J. Beveridge. 1990. Evaluation of freeze-substitution and conventional embedding protocols for routine electron microscopic processing of Eubacteria. J. Bacteriol. 172:2141-2149.

Hedderich, R., O. Klimmek, A. Kröger, R. Dirmeier, M. Keller and K.O. Stetter. 1999. Anaerobic respiration with elemental sulfur and with disulfides. FEMS Microbiol. Rev. 22:353-381.

Hohenberg, H., K. Mannweiler and M. Müller. 1994. High pressure freezing of cell supensions in cellulose capillary tubes. J. Microsc. 175:34-43.

Huber, R., D. Dyba, H. Huber, S. Burggraf and R. Rachel. 1998. Sulfur-inhibited Thermosphaera aggregans sp. nov., a new genus of hyperthermophilic archaea isolated after its prediction from environmentally derived $16 \mathrm{~S}$ rRNA sequences. Int. J. Syst. Bacteriol. 48:31-38.

Huber, H., S. Burggraf, T. Mayer, I. Wyschkony, R. Rachel and K.O. Stetter. 2000. Ignicoccus gen. nov., a novel genus of hyperthermophilic, chemolithoautotrophic Archaea, represented by two new species, Ignicoccus islandicus sp. nov. and Ignicoccus pacificus $\mathrm{sp}$. nov. Int. J. Syst. Evol. Microbiol. 50:2093-2100.

Humbel, B.M. and M. Müller. 1986. Freeze substitution and low temperature embedding. In The Science of Biological Specimen Preparation 1985. Eds. M. Müller, R.P. Becker, A. Boyde and J.J. Wolosewick. SEM, AMF O'Hare, IL, pp 175-183.

Kandler, O. and H. König. 1993. Cell envelopes of archaea: structure and chemistry. In The Biochemistry of Archaea (Archaebacteria). Eds. M. Kates, D.J. Kushner and A.T. Matheson. Elsevier, Amsterdam, pp 223-259. 
Kupper, J., W. Marwan, D. Typke, H. Grünberg, U. Uwer, M. Gluch and D. Oesterhelt. 1994. The flagellar bundle of Halobacterium salinarium is inserted into a distinct polar cap structure. J. Bacteriol. 176:5184-5187.

Luft, J.H. 1961. Improvements in epoxy resin embedding methods. J. Biophys. Biochem. Cytol. 9:409-414.

Müller, M. and H. Moor. 1984. Cryofixation of thick specimens by high pressure freezing. In The Science of Biological Specimen Preparation 1985. Eds. M. Müller, R.P. Becker, A. Boyde and J.J. Wolosewick. SEM, AMF O'Hare, IL, pp 131-183.

Nunn, D. 1999. Bacterial Type II protein export and pilus biogenesis: more than just homologies? Trends Cell Biol. 9:402-408.

Phipps, B.M., R. Huber and W. Baumeister. 1991. The cell envelope of the hyperthermophilic archaebacterium Pyrobaculum organotrophum consists of two regularly arrayed protein layers: three-dimensional structure of the outer layer. Mol. Microbiol. 5:253-265.

Rachel, R. 1999. Fine structure of hyperthermophiles. In Enigmatic Microorganisms and Life in Extreme Environments. Ed. J. Seckback. Kluwer Academic Publ., The Netherlands, pp 277-289.

Rieger, G., R. Rachel, R. Hermann and K.O. Stetter. 1995. Ultrastructure of the hyperthermophilic archaeon Pyrodictium abyssi. J. Struct. Biol. 115:78-87.

Rieger, G., K. Müller, R. Hermann, K.O. Stetter and R. Rachel. 1997. Cultivation of hyperthermophilic archaea in capillary tubes resulting in improved preservation of fine structures. Arch. Microbiol. 168:373-379.

Rothman, J.E. 1996. The protein machinery of vesicle budding and fusion. Protein Sci. 5:185-194.
Saxton, W.O. and W. Baumeister. 1982. The correlation averaging of a regularly arranged bacterial cell envelope protein. J. Microsc. 127:127-138.

Schirmer, T. 1998. General and specific porins from bacterial outer membranes. J. Struct. Biol. 121:101-109.

Sleytr, U.B. and P. Messner. 1988. Crystalline surface layers in procaryotes. J. Bacteriol. 170:2891-2897.

Söllner, T., S.W. Whiteheart, M. Brunner, H. Erdjument-Bromage, S. Geromanos, P. Tempst and J.E. Rothman. 1993. SNAP receptors implicated in vesicle targeting and fusion. Nature 362:318-324.

Stetter, K.O. 1996. Hyperthermophilic procaryotes. FEMS Microbiol. Rev. 18:149-158.

Stetter, K.O. 1999. Extremophiles and their adaptation to hot environments. FEBS Lett. 452:22-25.

Studer, D., M. Michel and M. Müller. 1989. High pressure freezing comes off age. Scanning Microsc. Suppl. 3:252-269.

Tiedemann, J., H. Hohenberg and R. Kollmann. 1997. High-pressure freezing of plant cells cultured in cellulose microcapillaries. J. Microsc. 189:163-171.

Völkl, P., R. Huber, E. Drobner, R. Rachel, S. Burggraf, A. Trincone and K.O. Stetter. 1993. Pyrobaculum aerophilum sp. nov., a novel nitrate reducing hyperthermophilic archaeum. Appl. Environ. Microbiol. 59:2918-2926.

Weibull, C.W. and A. Christiansson. 1986. Extraction of proteins and membrane lipids during low temperature embedding of biological material for electron microscopy. J. Microsc. 142:79-86. 

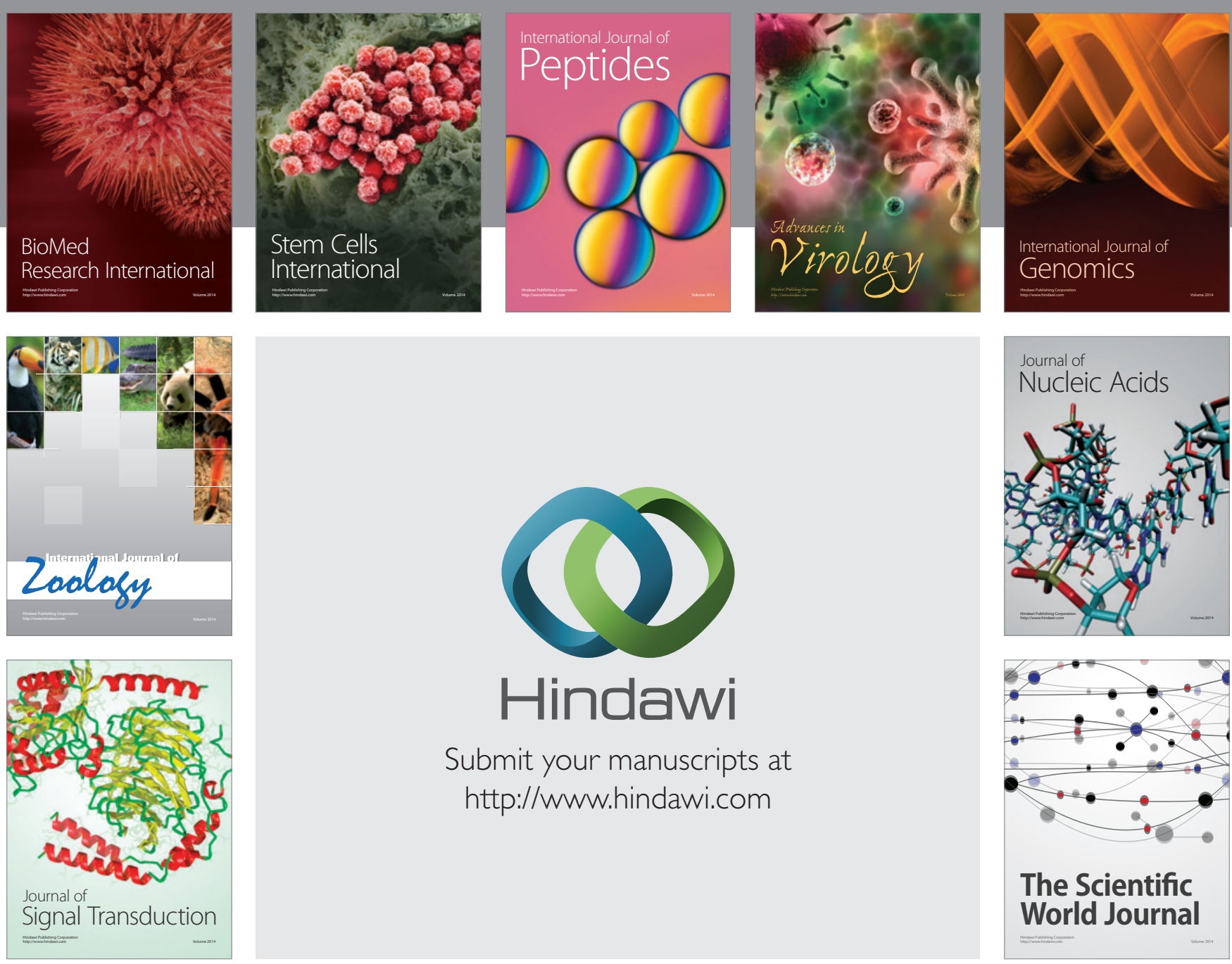

Submit your manuscripts at

http://www.hindawi.com
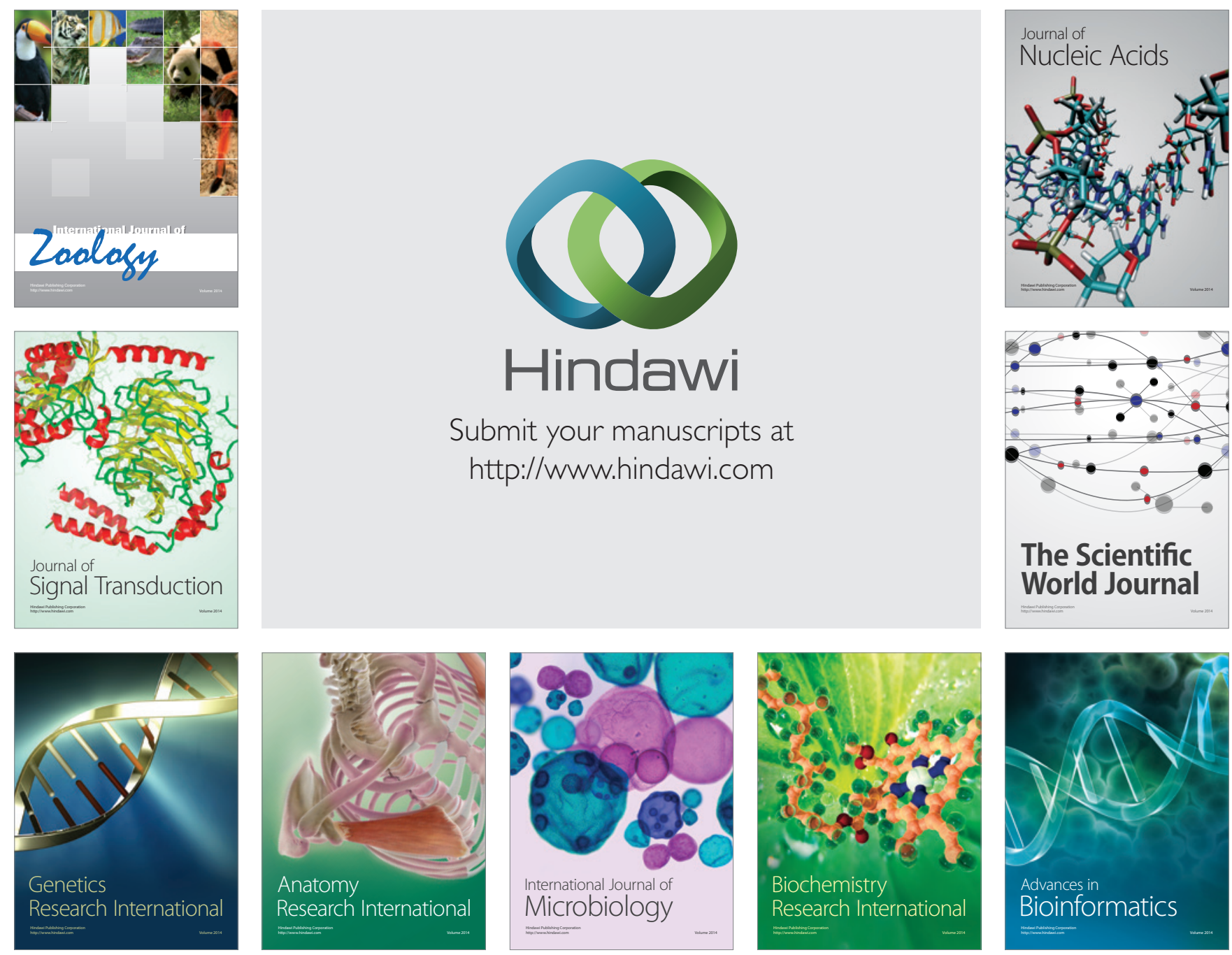

The Scientific World Journal
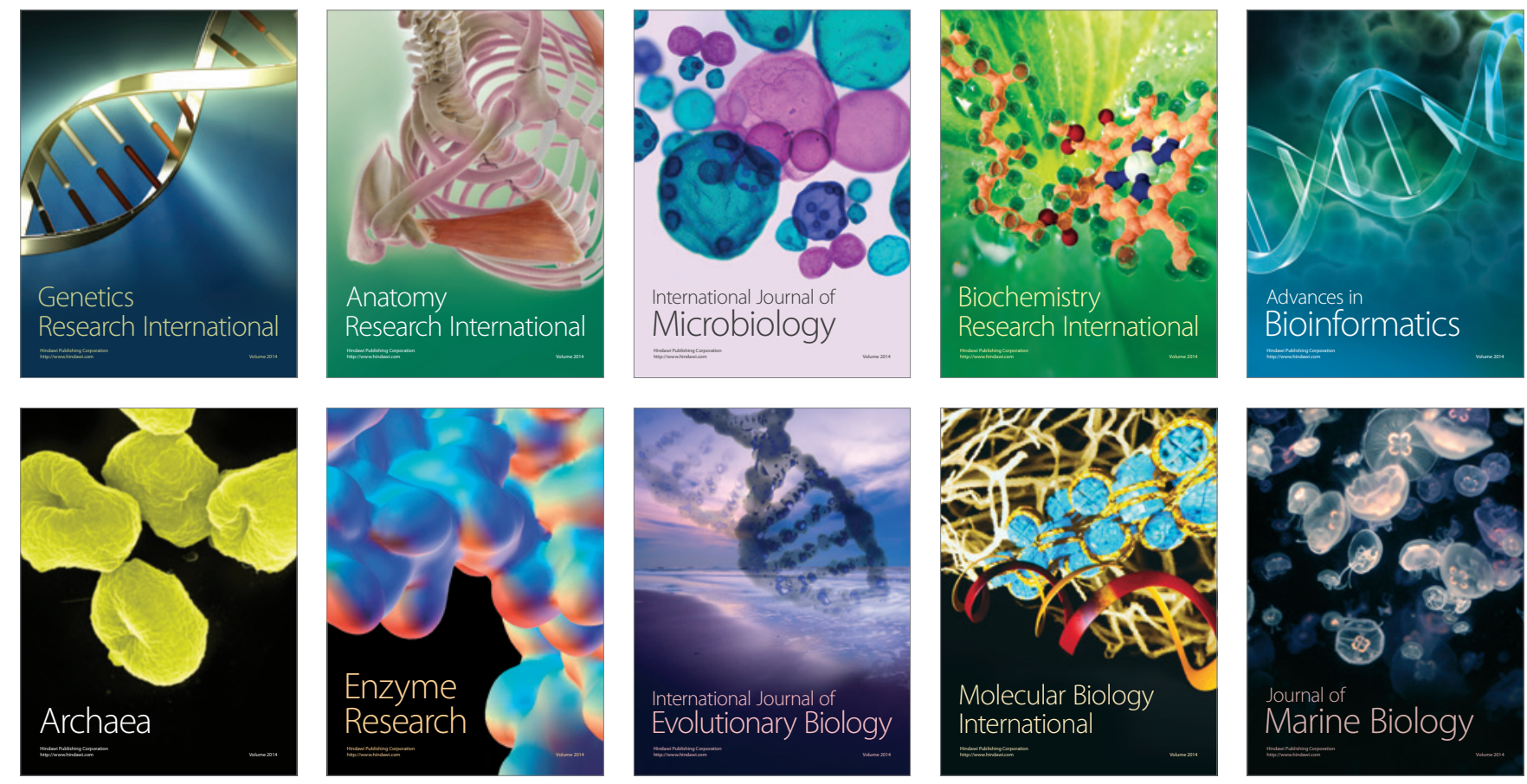